Article

\title{
An Autonomous Coil Alignment System for the Dynamic Wireless Charging of Electric Vehicles to Minimize Lateral Misalignment
}

\author{
Karam Hwang ${ }^{1}$, Jaeyong Cho ${ }^{1}$, Dongwook Kim ${ }^{1}$, Jaehyoung Park ${ }^{1}$, Jong Hwa Kwon ${ }^{2}$, \\ Sang Il Kwak ${ }^{2}$, Hyun Ho Park ${ }^{3}$ and Seungyoung Ahn ${ }^{1, *}$ \\ 1 Graduate School for Green Transportation, KAIST, Daejeon 34141, Korea; hwang8@kaist.ac.kr (K.H.); \\ fable@kaist.ac.kr (J.C.); dwkim88@kaist.ac.kr (D.K.); jaehyoung.park@kaist.ac.kr (J.P.) \\ 2 Electromagnetic Environment Research, ETRI, Daejeon 34129, Korea; hjkwon@etri.re.kr (J.H.K.); \\ sikwak@etri.re.kr (S.I.K.) \\ 3 Department of Electronic Engineering, University of Suwon, Hwaseong 18123, Korea; hhpark@suwon.ac.kr \\ * Correspondence: sahn@kaist.ac.kr; Tel.: +82-42-350-1263
}

Academic Editor: Sheldon S. Williamson

Received: 2 January 2017; Accepted: 2 March 2017; Published: 7 March 2017

\begin{abstract}
This paper proposes an autonomous coil alignment system (ACAS) for electric vehicles (EVs) with dynamic wireless charging (DWC) to mitigate the reduction in received power caused by lateral misalignment between the source and load coils. The key component of the ACAS is a novel sensor coil design, which can detect the load coil's left or right position relative to the source coil by observing the change in voltage phase. This allows the lateral misalignment to be estimated through the wireless power transfer (WPT) system alone, which is a novel tracking method for vehicular applications. Once misalignment is detected, the vehicle's lateral position is self-adjusted by an autonomous steering function. The feasibility of the overall operation of the ACAS was verified through simulation and experiments. In addition, an analysis based on experimental results was conducted, demonstrating that $26 \%$ more energy can be transferred during DWC with the ACAS, just by keeping the vehicle's load coil aligned with the source coil.
\end{abstract}

Keywords: electric vehicle (EV); dynamic wireless charging (DWC); wireless power transfer (WPT); power degradation; coil misalignment; magnetic sensing

\section{Introduction}

With the realization of electric vehicles (EVs) to reduce greenhouse gases, significant research and development directed towards improving EVs' feaatures has been conducted during recent years. However, one main disadvantage of EVs is their battery technology due to its high cost and limited driving range. To overcome the mentioned issues and minimize dependency on battery systems, many have looked into the utilization of infrastructure such as vehicle to grid (V2G) [1], or residential distribution grid systems [2]. Dynamic wireless charging (DWC) for EVs is another promising method of utilizing infrastructure to overcome battery issues in EVs. DWC is a wireless power transfer (WPT) system that allows EVs to be charged wirelessly while in motion. With DWC, EVs are less dependent on battery systems because they receive power from the road. As a result, EVs with DWC offer several advantages over conventional EVs such as lower vehicle cost and reduced charging time due to their smaller battery systems [3-5]. In light of the many benefits it can provide, extensive research on WPT and DWC has been conducted at various institutions around the globe. Further benefits can be realized when DWC is implemented as an EV charging lane on highways [6]. If a DWC lane is installed at 
strategic locations along the highway, the EV driving range can be extended, allowing owners to drive longer distances without the anxiety of having to worry about EV range [7].

However, the one main disadvantage of this DWC scheme is the reduction in received power and efficiency that occurs when there is a lateral misalignment of the vehicle's load coil and the source coil embedded under the road. The vehicle must be aligned within a certain range of the source coil to achieve high power in the load coil [8], which also maximizes the driving distance of the vehicle. Keeping the load coil of a vehicle aligned at all times with the source coil while in motion is very difficult, even for an experienced driver. In addition, attempting to keep the vehicle aligned with the source coil may distract the driver from oncoming traffic or obstacles and eventually lead to serious traffic accidents.

To minimize the problem with transferring power to the load coil due to lateral misalignment in WPT, many methods have been proposed to maximize lateral misalignment tolerance. Some proposed methods include changing the geometry of the coil [9], placing multiple coils in an orthogonal configuration [10] or an overlapping configuration [11], and even combining multiple coils of different geometry into one unit [12]. Another popular method is the utilization of ferromagnetic materials, where E-shape or U-shape ferrite cores $[13,14]$ are utilized at the load/source coils. Other methods also include active coil resonance frequency tuning circuits to maximize lateral tolerance $[15,16]$. All the proposed methods described above are constructive, but their implementation in vehicular applications can be very limited, due to the vehicle's limited installation space, weight constraints, as well as the dynamic driving environment. Even assuming that the proposed methods were implemented in the vehicle, misalignment would still be unavoidable as long as a person is controlling the vehicle. In addition, even a DWC-equipped EV with a high lateral misalignment tolerance $(45 \mathrm{~cm})$ will still have regions on a highway lane without wireless power delivery, as shown in Figure 1. And within the tolerance range, loss of power will still inevitably occur whenever the lateral misalignment increases.

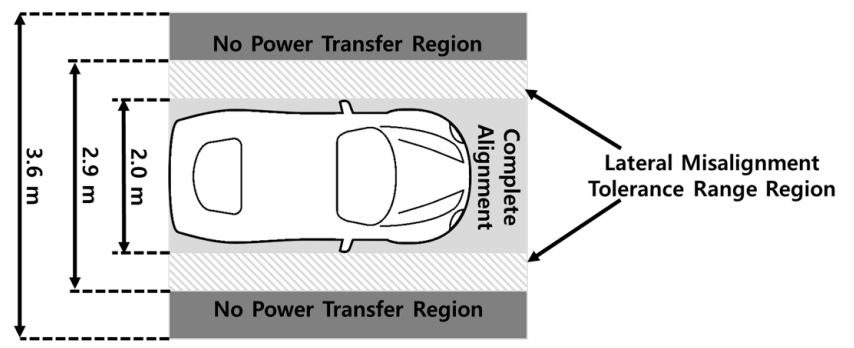

Figure 1. Power transfer coverage area on a $3.6 \mathrm{~m}$ width highway lane (based on FHWA standards [17]) for a WPT system with a $45 \mathrm{~cm}$ lateral misalignment tolerance. Equipped on a standard sized vehicle with a $2 \mathrm{~m}$ track width.

A vehicle tracking and autonomous guidance system using magnetic sensing can also be applied to reduce the DWC power transfer problem. The system concept is shown in Figure 2.

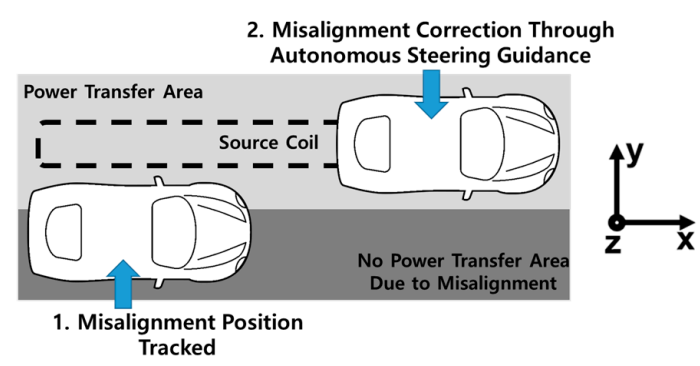

Figure 2. Concept of autonomous vehicle tracking and guidance to reduce degraded power transfer in a DWC system. 
The misalignment between the coils is detected using sensors and the vehicle's position is then adjusted by appropriate autonomous steering until the degraded power transfer in the DWC is restored to an optimum level.

Many vehicle tracking methods have been previously proposed where one popular method is using global positioning system (GPS) sensors and/or magnetic markers [18]. Other tracking methods specific for DWC applications are also proposed in [19-21], where a radio-frequency identification (RFID) tag and reader were implemented. However, one disadvantage of magnetic markers or RFID tags is the rapid decay in the strength of the magnetic field with distance, as the detector moves away from the marker/tag range. Therefore, the magnetic markers or RFID tags have to be placed close to each other in order to achieve high tracking resolution, which increases overall construction costs. To reduce construction costs, magnetic sensing hardware with a wider detection range has been proposed as shown in [22] or using a Gaussian function-based algorithm to have higher detection accuracy [23]. However, this leads to bulkier sensor hardware which is not desirable, especially when vehicle space is very limited with the DWC system installed.

Another method of magnetic tracking is the autonomous coil alignment system (ACAS), which has been proposed by the authors of this paper in [24]. ACAS is a novel method of tracking a vehicle's misalignment position by only measuring the voltage in the vehicle's load coil. Since this method only utilizes the existing DWC system, the use of external magnetic or RFID markers is eliminated, which leads to a significant reduction in implementation costs for the magnetic tracking functions. One main challenge of this approach is how to determine whether the load coil was misaligned to the left or the right side relative to the center of the source coil. This is because the voltage readings are nearly identical on both sides. The proposed two-sensor coil unit design in [24] detected the left/right side position by calculating the difference in the voltage readings of the two sensor coils. Even though the operational feasibility of the ACAS was verified, it was only compatible with a specific DWC system, and its algorithm was very complex. If any significant changes were made to the DWC system, the accuracy of position tracking could be affected.

The ACAS proposed in this paper is a significant improvement over the previous design described in [24]. It is a single-sensor coil unit, and detects change in voltage phase to identify the left/right side position rather than the voltage difference between two sensor coils. With the new ACAS design, the complexity of the algorithm and hardware can be significantly reduced, providing a more reliable system. This also allows wider application compatibility with other DWC systems with varying specifications.

The paper is organized as follows: an analysis of power loss due to lateral misalignment, as well as the reasons for proposing the ACAS system, are discussed in Section 2. In Section 3, the main components of the ACAS are discussed and its concept feasibility is verified by simulation. The operational feasibility of the ACAS is further verified by experiments in Section 4 . Conclusions are presented in Section 5.

\section{Analysis of Power Loss Due to Lateral Misalignment in Dynamic Wireless Charging (DWC) Systems}

DWC can be viewed as a general WPT system circuit model, shown in Figure 3, which consists of a source coil and a load coil section. The efficiency of the WPT system is defined by the ratio of the power delivered from the source coil, $P_{S}$, and the load coil, $P_{L}$, as follows:

$$
\eta=\frac{P_{L}}{P_{S}}
$$

From Equation (1), $P_{S}$ and $P_{L}$ can be defined as:

$$
P_{S}=I_{1} V_{S}=\left(\frac{R_{L}+\frac{1}{j \omega C_{L}}+j \omega L_{L}}{j \omega M} I_{2}\right) V_{S}
$$




$$
P_{L}=I_{2} V_{L}=I_{2}^{2} R_{L}=\left(\frac{j \omega M}{R_{L}+\frac{1}{j \omega C_{L}}+j \omega L_{L}} I_{1}\right)^{2} R_{L}
$$

where $R_{S}, C_{S}, L_{S}$ represent the resistor, capacitor, or inductor components of the source coil, respectively, and $R_{L}, C_{L}, L_{L}$ represent the resistor, capacitor, or inductor components of the load coil, respectively. $\omega$ represents the frequency, and $I_{1}, I_{2}$ represent the currents flowing in the source coil and load coil, respectively. $M$ is the mutual inductance between the source coil and load coil, which is expressed as follows:

$$
M=k \sqrt{L_{S} L_{L}}
$$

where $k$ is a coupling coefficient.

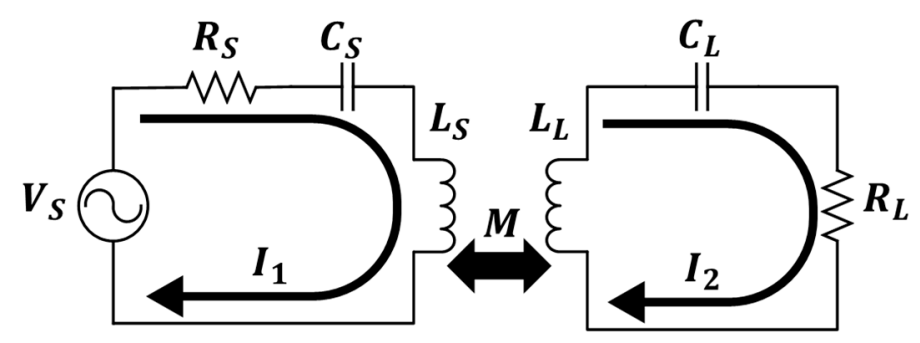

Figure 3. General circuit model for wireless power transfer (WPT).

The mutual inductance between the source coil and the load coil greatly affects the received power at the load coil as well as the overall efficiency of the WPT system, as noted in previous works $[10,25]$. Therefore, it is important for any WPT system to maintain the highest mutual inductance to maximize the received power and efficiency to the load coil. Based on the Neumann formula, the mutual inductance shown in (4) can also be described as the number of flux linkages in the load coil resulting from the current flowing from the source coil [10]:

$$
M=\frac{\mu_{0}}{4 \pi} \oint \oint \frac{d l_{S} d l_{L}}{\left|r_{S L}\right|}
$$

where $\mu_{0}, d l_{S}$ and $d l_{L}$ represent the permeability of free-space, and the infinitesimal segments of the source coil and load coil, respectively, while $\left|r_{S L}\right|$ represents the distance between the source coil and the load coil segments, which can also be seen as misalignment. Assuming that a constant current is applied, the only variable that will affect $M$ is $\left|r_{S L}\right|$. Therefore, from (1) to (5), it can be determined that increased misalignment reduces $M$, thus reducing the magnitude of received power at the load coil and the overall WPT efficiency.

Based on (5), there are several factors that will change the magnitude of $\left|r_{S L}\right|$ : vertical, lateral, and angular misalignment. However, not all of these factors are likely to be observed in practice, for the following reasons: because the load coil is fixed to the underbody of a vehicle, the misalignment between the source coil and load coil is highly dependent on vehicle movement. When a vehicle is operating on highways or on roads that are flat, it can be assumed that the vertical misalignment and angular misalignment relative to the $\mathrm{x}$ and $\mathrm{y}$ axes will have small variations.

The two factors that remain are the lateral, and angular misalignment relative to the $z$ axis. Between these two factors, the dominant factor that will affect $M$ is the lateral misalignment. To prove this statement, a 3-D electromagnetic (3-D EM) simulation was conducted. A general rectangular shaped load coil placed on top of the source coil lines was designed to replicate the DWC system shown in Figure 4. Its electrical parameters are presented in Table 1 as well. 


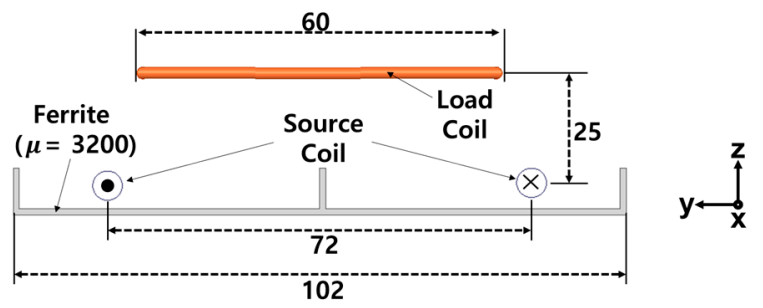

Figure 4. 3-D EM simulation model of the source coil and load coil and their dimensional parameters (in $\mathrm{cm}$ ).

Table 1. Parameter setup for the 3-D EM simulation.

\begin{tabular}{cccc}
\hline Parameter & Source Coil & Load Coil & Sensor Coil \\
\hline \# of turns & 8 & 50 & 10 \\
Inductance & $116 \mu \mathrm{H}$ & $2.35 \mathrm{mH}$ & $732 \mathrm{nH}$ \\
Operating frequency & & $20 \mathrm{kHz}$ & \\
Current through source coil & & $200 \mathrm{~A}$ & \\
\hline
\end{tabular}

The simulation was conducted to observe the changes in $M, k$ and the load coil's received power resulting from a lateral misalignment of $-50 \mathrm{~cm}$ to $50 \mathrm{~cm}$, and also an angular misalignment of 0,10 , and 20 degrees relative to the $z$ axis. The simulation only considered an angular misalignment up to 20 degrees, because an angular misalignment greater than the stated value can be considered an extreme steering angle for a vehicle moving at high speeds.

The changes in $M$, and $k$ from the lateral and angular misalignments are shown in Figure 5 . There are slight variations with increased angular misalignment, but it can be seen that lateral misalignment is the dominant factor in reducing $M$. Therefore, the proposed ACAS was designed to minimize lateral misalignment to allow higher $M$ so that higher power will be received at the load coil, increasing overall efficiency.
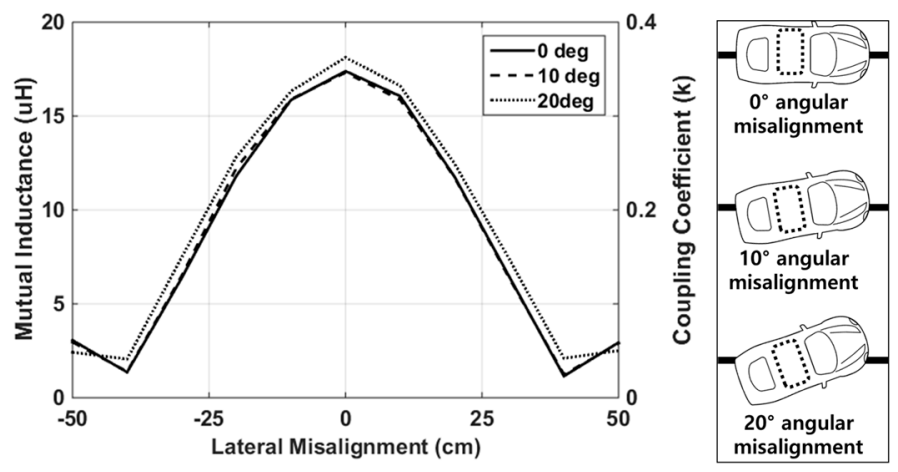

Figure 5. 3-D EM simulation result showing the change in the mutual inductance and coupling coefficient due to lateral misalignment and angular misalignment.

\section{Concept of the Autonomous Coil Alignment System (ACAS)}

Figure 6 shows a general block diagram of the proposed ACAS. It is divided into three parts: the ACAS sensor coil unit, the lateral position detection unit, and the fuzzy steering controller. The lateral misalignment position is estimated by the sensor coil unit and further processed by the lateral misalignment detection unit. Based on the detected lateral misalignment, the fuzzy steering controller will send steering commands to the electronic power steering system (EPS), after which the vehicle is steered autonomously to correct the misalignment. EPS is already used in most EVs and is being equipped in most newly manufactured commercial vehicles as well. In case an obstacle is 
present which obstructs the path of maximum charging, the user must have the ability to interrupt the operation of the ACAS. Therefore, the ACAS is designed so that the user can enable or disable the operation of the ACAS at any time, as shown in Figure 6.

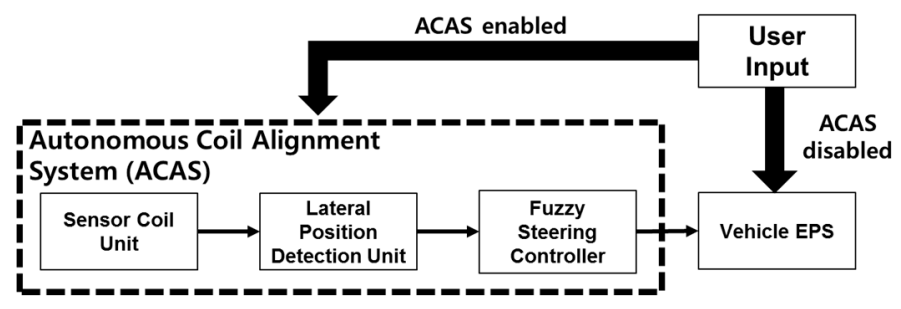

Figure 6. Block diagram of the ACAS.

\subsection{ACAS Sensor Coil Unit}

In the ACAS, the range of lateral misalignment is estimated based on voltage readings alone. Based on (3), the voltage on the load coil can be expressed as follows:

$$
V_{L}=\frac{j \omega M}{R_{L}+\frac{1}{j \omega C_{L}}+j \omega L_{L}} I_{1} R_{L}
$$

When a constant current source is being supplied to the source coil, the dominant parameter that will change the load coil voltage is $M$. To prove this statement, a 3-D FEM simulation was conducted again using the same model shown in Figure 4 and Table 1, to measure the induced voltage in the load coil. The results are shown in Figure 7. It can be seen in the graphed trends that the peaks of the mutual inductance and the induced voltage in the load coil are nearly identical; thus, it shows that the lateral misalignment can be identified through the load coil voltage alone.

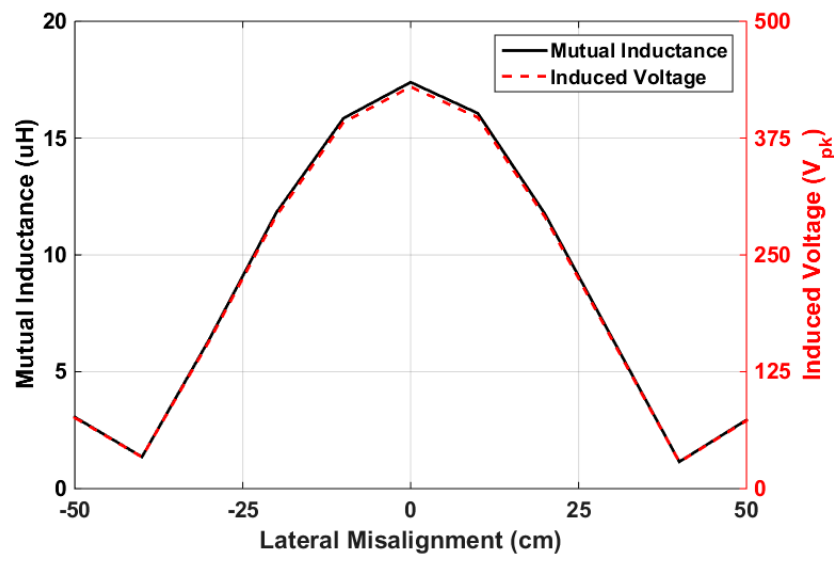

Figure 7. 3-D FEM simulation result showing a waveform comparison of the mutual inductance and the induced voltage on the load coil.

As mentioned in the introduction, the main challenge is to determine whether the load coil is misaligned to the left or the right side. To solve this problem, a sensor coil unit is proposed, which is composed of a single coil unit wound around the middle of the leading section of the load coil, as illustrated in Figure 8.

With this configuration, the load coil's left/right position can be determined based on the source coil's reference. The sensor coil does not occupy much space, and the number of turns for the coil is sufficient to induce a signal strong enough for the ACAS main controller to recognize, while small enough to not disrupt the power transfer between the source coil and the load coil. 


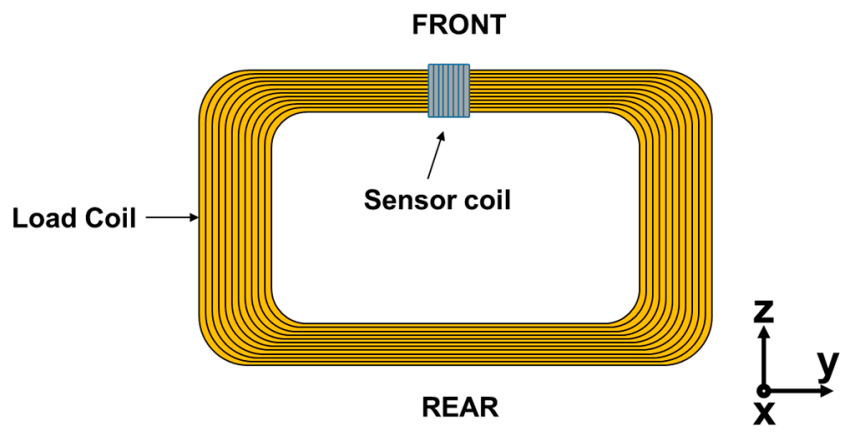

Figure 8. Configuration of the sensor coil within the load coil. Shown from a top view perspective.

Figure 9a shows how the load coil/sensor coil unit is implemented under the vehicle body when the load coil and source coil are in perfect alignment. In addition, it shows a cross section along the $\mathrm{x}-\mathrm{y}$ plane of the source coil as well.

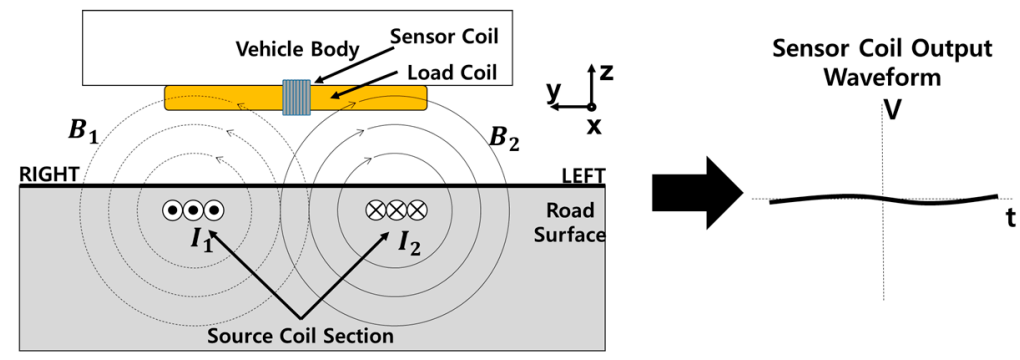

(a)

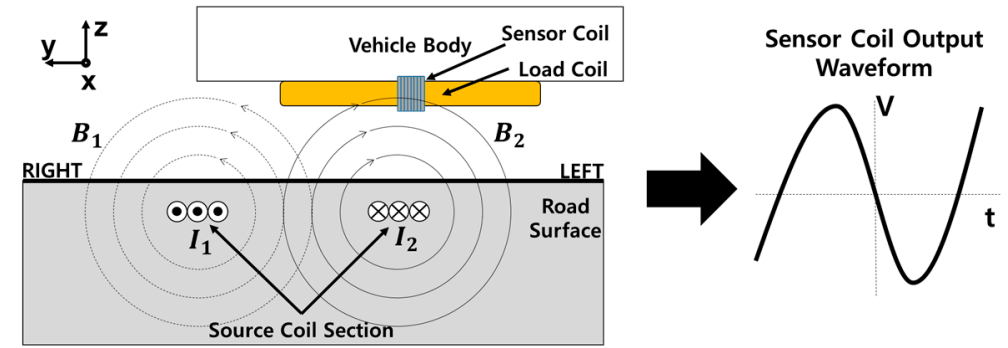

(b)
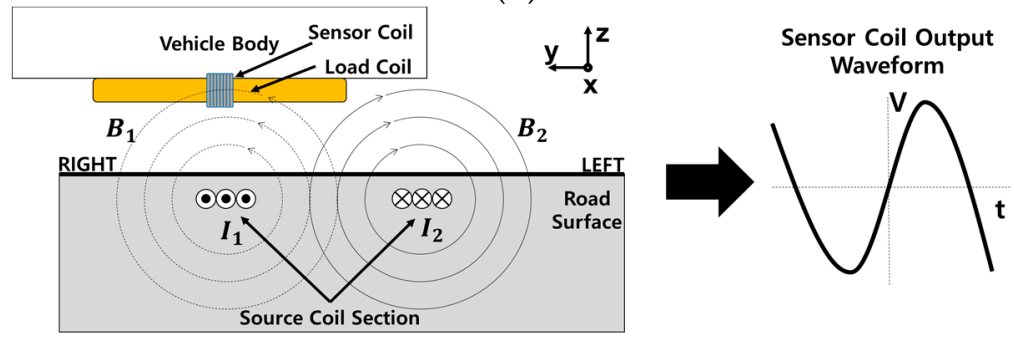

(c)

Figure 9. The resulting voltage waveform of the sensor coil in different positions (a) when the load coil is aligned with the source coil (origin point); (b) when the load coil is misaligned towards the left, and (c) when the load coil is misaligned to the right.

As shown in Figures 8 and 9, the sensor coil is placed in a specific location, where the loop of the sensor coil is facing in the $y$-axis direction. Viewing the source coil in Figure 9, the magnetic field generated on the source coil, $\mathbf{B}_{\mathbf{S}}$, can be expressed in vector form as follows:

$$
\mathbf{B}_{\mathrm{S}}=\mathbf{B}_{1}+\mathbf{B}_{2}
$$


where $\mathbf{B}_{1}$ and $\mathbf{B}_{2}$ are the right and left magnetic fields, respectively, as shown in Figure 9. When viewed from the $y$-axis direction, from the direction the loop of the sensor coil is facing, $\mathbf{B}_{\mathbf{S}}$ can be expressed in vector form as follows:

$$
\mathbf{B}_{\mathbf{y}}^{\mathbf{s}}=\mathbf{B}_{\mathbf{y}}^{\mathbf{1}}+\mathbf{B}_{\mathbf{y}}^{\mathbf{2}}=-\frac{\mu_{0} I_{1}}{2 \pi r_{1}} \sin \theta_{1}+\frac{\mu_{0} I_{2}}{2 \pi r_{2}} \sin \theta_{2}
$$

In (8), $I_{1}, I_{2}, \theta_{1}$ and $\theta_{2}$ are the current flow and the angle needed to generate $\mathbf{B}_{\mathbf{1}}$ and $\mathbf{B}_{2}$, respectively. It should be noted that $I_{1}$ and $I_{2}$ have the same magnitudes but flow in opposite directions. $\mu_{0}$ is the free-space permeability and $r_{1}, r_{2}$ are the reference point distances of $\mathbf{B}_{1}$ and $\mathbf{B}_{2}$, respectively. In Figure 9 a, the magnetic field sensed by the sensor coil is near zero because $\mathbf{B}_{\mathbf{1}}$ and $\mathbf{B}_{\mathbf{2}}$ cancel each other out. As the sensor coil moves towards the left, as shown in Figure 9b, the sensor coil is relatively more exposed to the $\mathbf{B}_{\mathbf{2}}$ magnetic field, thus the magnitude of $\mathbf{B}_{\mathbf{2}}$ will be more dominant than $\mathbf{B}_{\mathbf{1}}$. The opposite phenomenon will occur when the sensor coil moves towards the right, where the magnitude of $\mathbf{B}_{1}$ will be more dominant than $\mathbf{B}_{2}$, as shown in Figure 9c.

The induced voltage in the sensor coil, $V_{s e}$, can be expressed as follows:

$$
V_{s e}=-\frac{d \Phi}{d t}=-\frac{d \mathbf{B}_{\mathbf{S}} A}{d t}
$$

where the equation is based on Faraday's law. $\Phi, t$ and $A$ represent the magnetic flux, time, and cross sectional area of the sensor coil, respectively. When the load coil is misaligned to the left or right, the phase angle difference between the sensor coil will always have a \pm 90 degree difference, respectively. The phase difference will only change when the load coil is shifted from the right region to the left region, or vice versa. Under these conditions, the difference in phase when the coil is misaligned to the left (shown in Figure 9b) and right (shown in Figure 9c) will be around 180 degrees.

Verification of the ACAS Sensor Coil Unit through Simulation

3-D EM simulations were conducted to verify that the placement of the sensor coil does not have much influence on the power transfer between the source coil and load coil, and also to verify the concept shown in Figure 9. The sensor coil was added to the simulation model shown in Figure 4 to match the configuration shown in Figure 8. The sensor coil parameters were as listed in Table 1. Figures 10 and 11 show comparisons of the induced voltage and magnetic flux density of the load coil with the sensor coil, and the load coil without the sensor coil, respectively, when a lateral misalignment occurs from $-50 \mathrm{~cm}$ to $50 \mathrm{~cm}$.

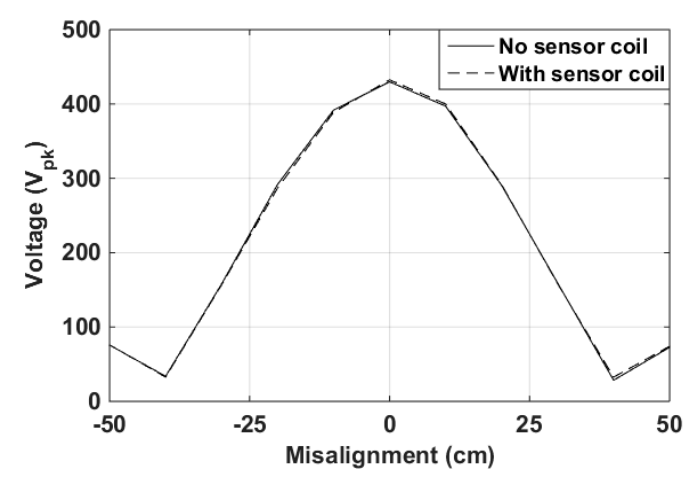

Figure 10. Simulation results showing induced voltage vs. lateral misalignment. A comparison of load coils with and without the sensor coil.

Based on Figure 10, the two output waveforms are nearly identical, and the magnetic flux density comparison in Figure 11 shows that the existence of the sensor coil unit creates almost no interference with the magnetic flow between the load coil and sensor coil. This verifies that the placement of the sensor coil has little effect on the performance of the overall WPT system. 


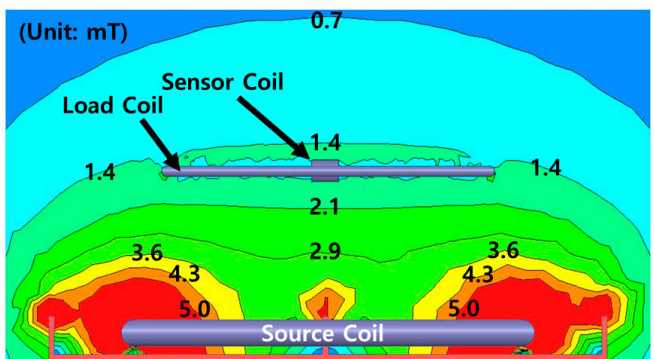

(a)

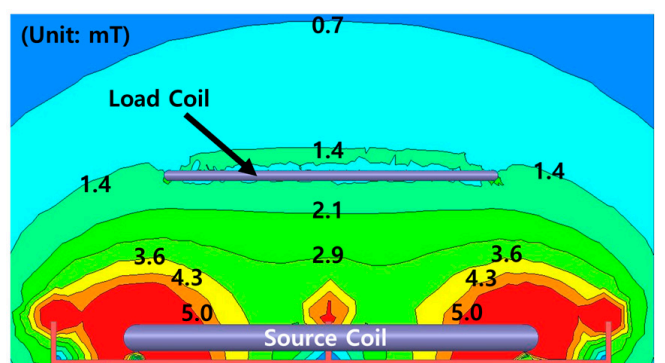

(b)

Figure 11. Simulation results showing the magnetic flux density for the load coil (a) with the sensor coil unit and (b) without the sensor coil unit.

The output voltage waveforms generated from the sensor coil when it is misaligned to the left or right side are shown in Figure 12. The results show that the resulting voltage for the left side and right side maintains a 90 degree phase difference, thus validating the theory shown in Figure 9, and clearly distinguishing the left/right side regions regardless of position. It can also be observed that the relationship between the sensor coil's induced voltage and lateral misalignment is non-linear. However, this information can be neglected because the left/right directions can be clearly identified by the sensor coil. With the left/right information, the exact lateral misalignment position can be identified by measuring the voltage through the load coil, which is further processed in the ACAS lateral position detection unit.

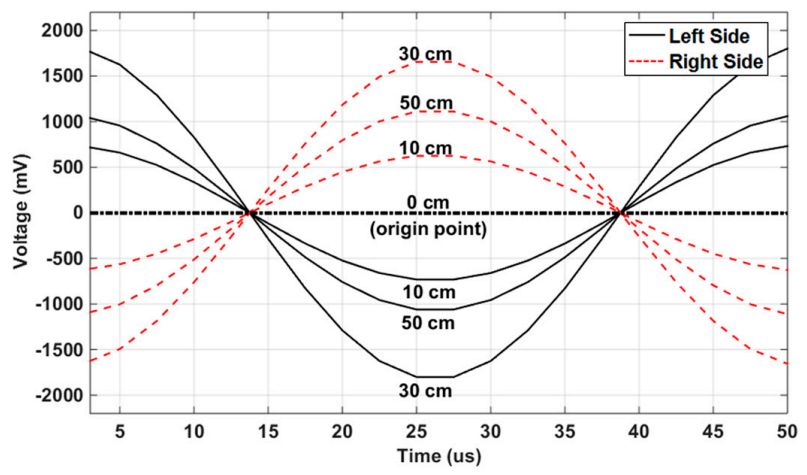

Figure 12. Simulated sensor coil voltage output vs. time, showing the left side and right side positions can be clearly identified.

\subsection{ACAS Lateral Position Detection Unit}

As mentioned in Section 3.1, the left and right sides can be detected based on the phase difference. The ACAS lateral position detection unit is responsible for converting those values into information that can be processed by the ACAS fuzzy steering controller. The block diagram of the ACAS lateral position detection unit is shown in Figure 13.

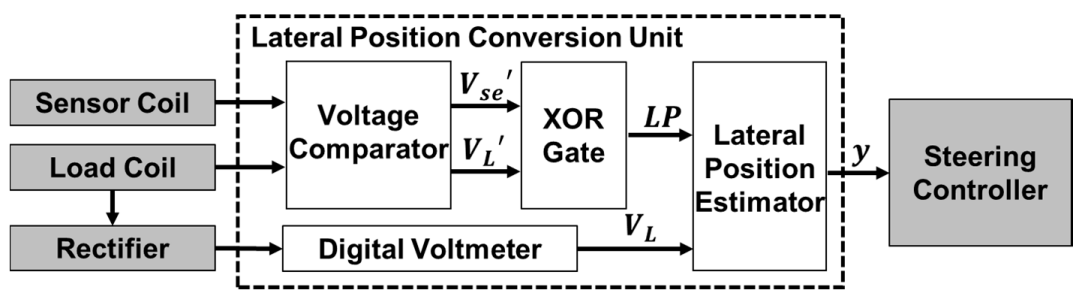

Figure 13. Block diagram showing the ACAS lateral position detection unit. 
It consists of a voltage comparator, exclusive OR (XOR) gate, and digital voltmeter. The load coil waveform and the sensor coil waveform are each converted into logic square waveforms through the voltage comparators as shown in the block diagram in Figure 13. From here, the converted sensor coil logic signal, $V_{s e}{ }^{\prime}$, and the converted load coil logic signal, $V_{L}{ }^{\prime}$ are sent into the XOR gate, where the two signals are compared with each other to determine the left or right lateral position. Since the phase of the load coil remains unchanged, the load coil voltage (in AC form) can be used as a reference to determine the phase change in the sensor coil, as shown in Figure 9. The logic flow of the XOR gate output used to determine the left and right position is shown in Figure 14. Two input signals $V_{s e}{ }^{\prime}$, and $V_{L}{ }^{\prime}$ are sent as input into the XOR gate. Based on the nature of operation of the XOR gate, the output at the XOR gate, expressed as LP, is either a $5 \mathrm{~V}$ output (logic $\mathrm{HI}$ ) or a $0 \mathrm{~V}$ (logic LO) signal to indicate left or right, respectively.

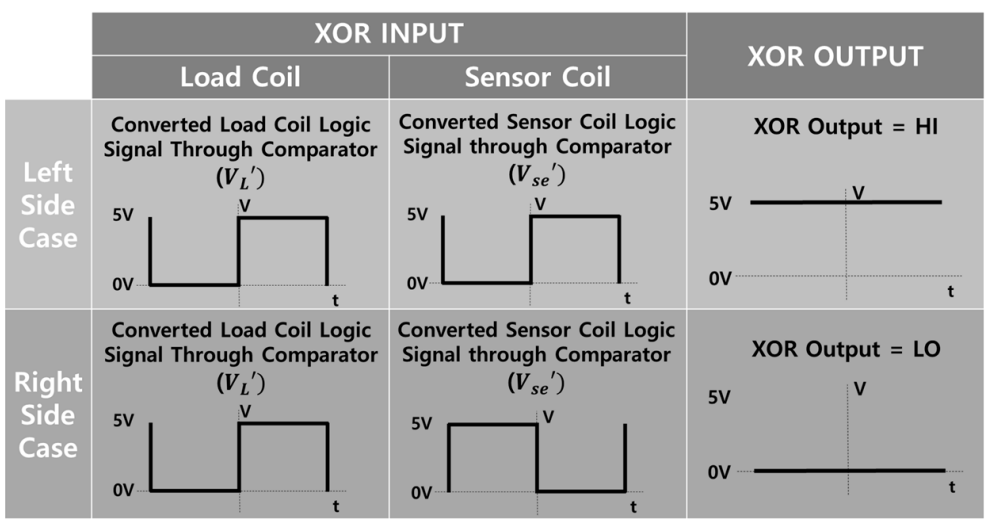

Figure 14. The XOR gate output from the converted load coil and the sensor coil logic signal inputs based on left or right side lateral misalignment.

With the left or right side detected, the location of the lateral misalignment, $y$, can be determined as follows:

$$
y=\left\{\begin{array}{c}
-f\left(V_{L}\right) \text { if } L P=H I \\
f\left(V_{L}\right) \text { if } L P=L O
\end{array}\right.
$$

where $f\left(V_{L}\right)$ is a function that represents the relationship between the load coil voltage and the lateral position, $y$. With the known left/right position, the lateral misalignment $y$ is estimated and directly fed as input into the ACAS fuzzy steering controller.

\subsection{ACAS Fuzzy Steering Controller}

The lateral misalignment is estimated based on the voltage measurement alone, but irregularities can occur in the reading of the angular misalignment of the load coil, or even because of the non-linear characteristics of the DWC system. In addition, the source coil used in DWC systems is typically installed in segments to maximize efficiency, as described in $[12,26]$. Thus, it can be expected that the voltages generated in each segment will not be entirely identical. To tolerate such characteristics, a fuzzy logic based steering control method is used in the ACAS, because it can provide better dynamic response compared to other conventional controllers $[27,28]$. The fuzzy logic steering controller used for the ACAS in this paper was previously introduced by the authors. In the present study, only experiments to verify the performance of the fuzzy steering controller were conducted. The design process and simulation results can be obtained in [24].

\section{Experimental Validation}

To observe and validate the overall performance of the ACAS, a smaller scale DWC system and experimental vehicle were constructed, and two experiments were conducted. In the first experiment, 
the main purpose was to validate the power loss due to lateral misalignment, and also to validate the operating concept of the proposed sensor coil. Because the first experiment operated near a $90 \mathrm{~W}$ power level, a static load (10 $\Omega$ resistor) was used instead of the experimental vehicle because the stated power level exceeded the recommended operation settings used in the experimental vehicle. For the second experiment, the main purpose was to validate the overall operating concept of the ACAS. The same DWC system from the first experiment were used, but the power level was reduced to $10 \mathrm{~W}$, so that the experimental vehicle could be used. The operation of the experimental vehicle can be viewed in the video shown in S1.

\subsection{Experimental Setup}

A DWC system was constructed in laboratory scale to validate the operation of the ACAS system. The source coil unit and the load coil/sensor coil unit are shown in Figure 15. The electrical and dimension parameters of the coil units are shown in Table 2.

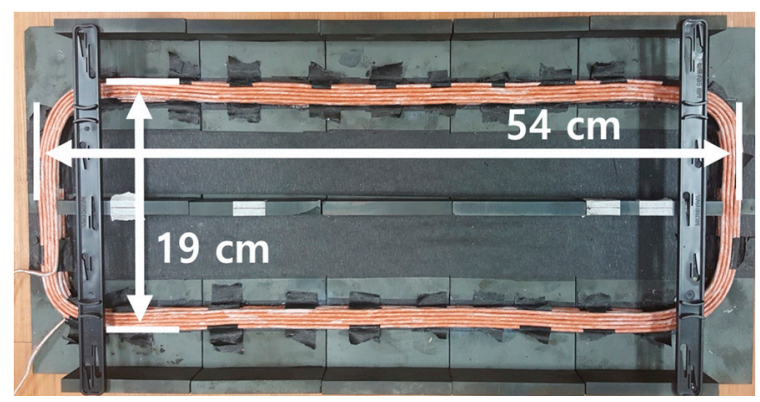

(a)

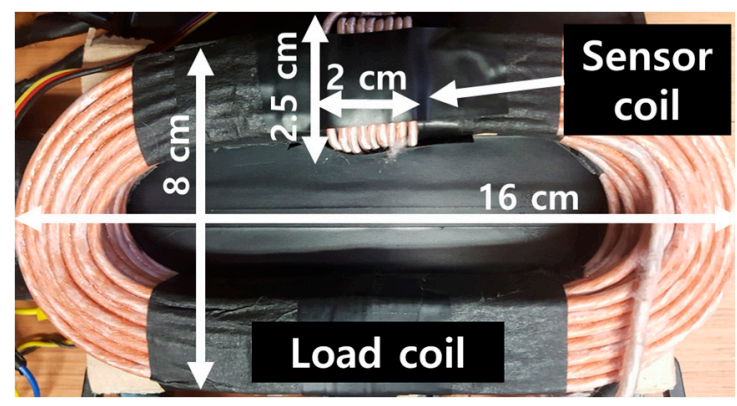

(b)

Figure 15. Coil construction of the (a) source coil unit and (b) load coil/sensor coil unit.

Table 2. Dimensions and electrical parameters of the coils used in the experiment.

\begin{tabular}{cccc}
\hline Parameter & Source Coil & Load Coil & Sensor Coil \\
\hline Dimensions $(\mathrm{W} \times \mathrm{L} \times \mathrm{H})$ & $19.0 \mathrm{~cm} \times 54.0 \mathrm{~cm} \times 1.5 \mathrm{~cm}$ & $8.0 \mathrm{~cm} \times 16.0 \mathrm{~cm} \times 2.0 \mathrm{~cm}$ & $2.0 \mathrm{~cm} \times 2.5 \mathrm{~cm} \times 2.5 \mathrm{~cm}$ \\
\hline \# of turns & 20 & 42 & 10 \\
\hline inductance & $590.00 \mu \mathrm{H}$ & $186.15 \mu \mathrm{H}$ & $2.45 \mu \mathrm{H}$ \\
\hline
\end{tabular}

The source coil unit and the load coil each consist of ferrite core assemblies as shown in Figure 16. In case of the source coil ferrite core assembly, it consists of ferrite blocks of two different types, which has been identified as ferrite block type A and type B, respectively. The difference between the two ferrite blocks are its dimensions, while the other specifications are identical, as shown in Table 3.

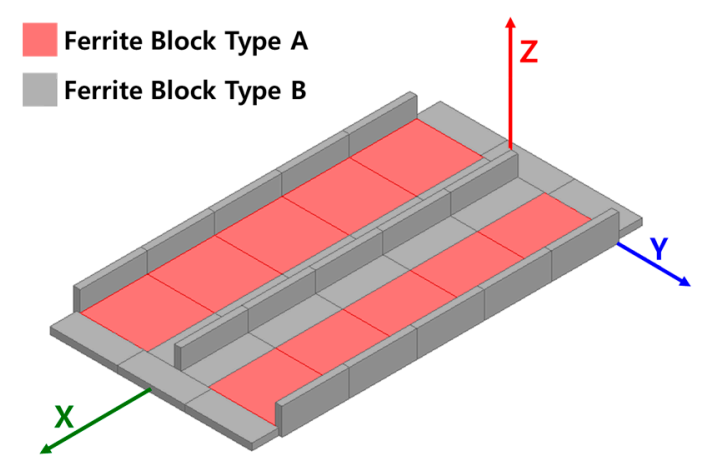

(a)

\section{Ferrite Block Type A}

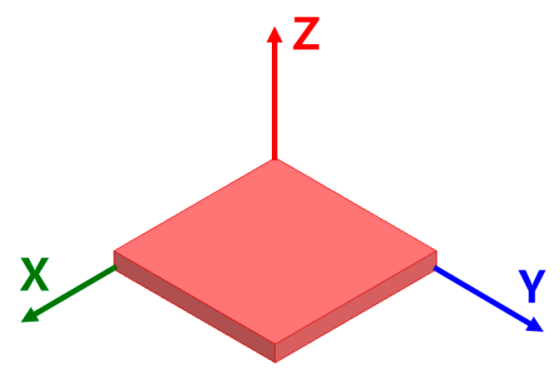

(b)

Figure 16. Ferrite core assemblies for the (a) source coil and (b) load coil unit. 
Table 3. Material characteristics of ferrite blocks types A and B identified in Figure 16.

\begin{tabular}{ccc}
\hline Parameter & Ferrite Block Type A & Ferrite Block Type B \\
\hline Dimensions $(\mathrm{W} \times \mathrm{L} \times \mathrm{H})$ & $10.0 \mathrm{~cm} \times 10.0 \mathrm{~cm} \times 1.0 \mathrm{~cm}$ & $10.0 \mathrm{~cm} \times 4.0 \mathrm{~cm} \times 1.0 \mathrm{~cm}$ \\
Material & \multicolumn{2}{c}{ Manganese-Zinc $(\mathrm{Mn}-\mathrm{Zn})$} \\
Permeability $(\mu)$ & \multicolumn{2}{c}{3200} \\
Saturation flux density $\left(\mathbf{B}_{\mathbf{S}}\right)$ & \multicolumn{2}{c}{$520 \mathrm{mT}$} \\
\hline
\end{tabular}

The laboratory scale vehicle is shown in Figure 17. The lateral position detection unit as well as the fuzzy steering controller unit described in [24] were programmed into the microcontroller as shown in Figure 17a, and the constructed load coil/sensor coil unit was mounted underneath the vehicle as shown in Figure 17b. The complete experimental setup is shown in Figure 18, where a $20 \mathrm{kHz}$ inverter was used as the main source for delivering power wirelessly from the source coil to the load coil. It can also be observed that an acrylic plate has been placed between the source coil and load coil. The mentioned acrylic plate was moved laterally left and right to generate misalignment between the source coil and load coil.

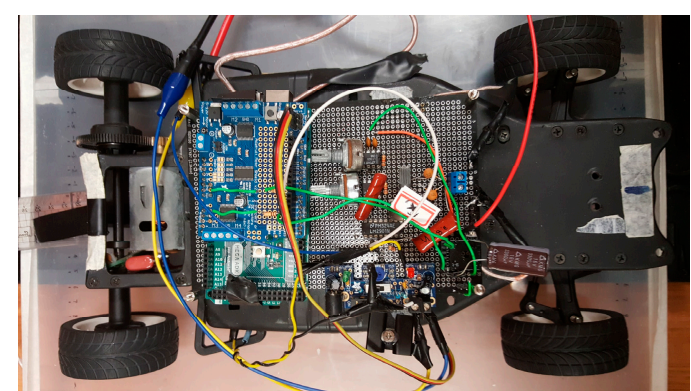

(a)

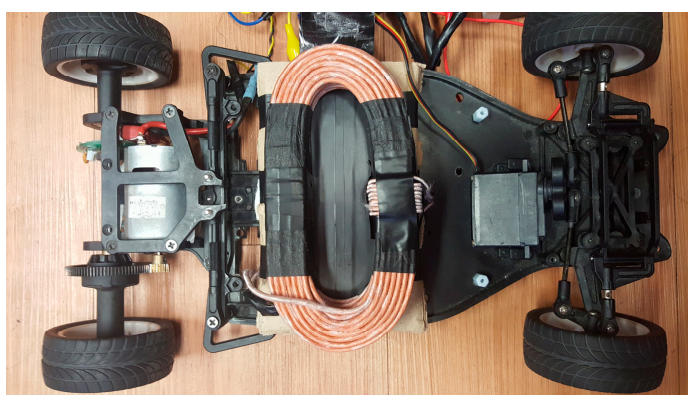

(b)

Figure 17. Experimental vehicle. (a) Top view, showing the microcontroller unit; (b) Bottom view, showing the load coil/sensor coil unit.

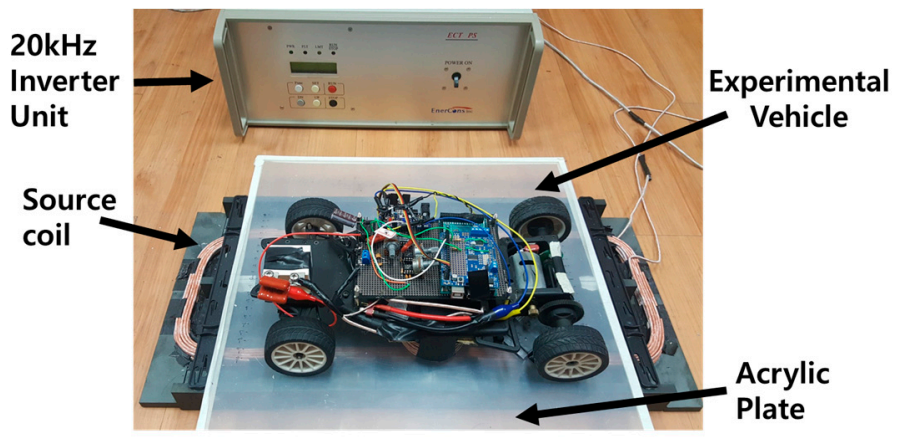

Figure 18. Experimental setup of the experimental vehicle with the ACAS unit.

Figure 19 shows the schematic of the overall experiment, and the values of parameters shown are listed in Table 4 . The $V_{S}$ is the main voltage source generated from the $20 \mathrm{kHz}$ inverter unit, and it was adjusted to generate $90 \mathrm{~W}$ and $10 \mathrm{~W}$ at the load for the first experiment and second experiment, respectively. During the construction phase of the experimental vehicle, it was observed that a lot of noise was generated which affected the sensor coil's measurement accuracy. Therefore, an active non-inverting (NI) low-pass filter (LPF) was constructed using an instrumentation amplifier, and placed between the sensor coil and the voltage comparator as shown in Figure 19. The R, C values for the LPF, assigned as $R_{L P F}$, and $C_{L P F}$, respectively, was assigned to match the cut-off frequency of $20 \mathrm{kHz}$ as close as possible, which is also listed in Table 4. 


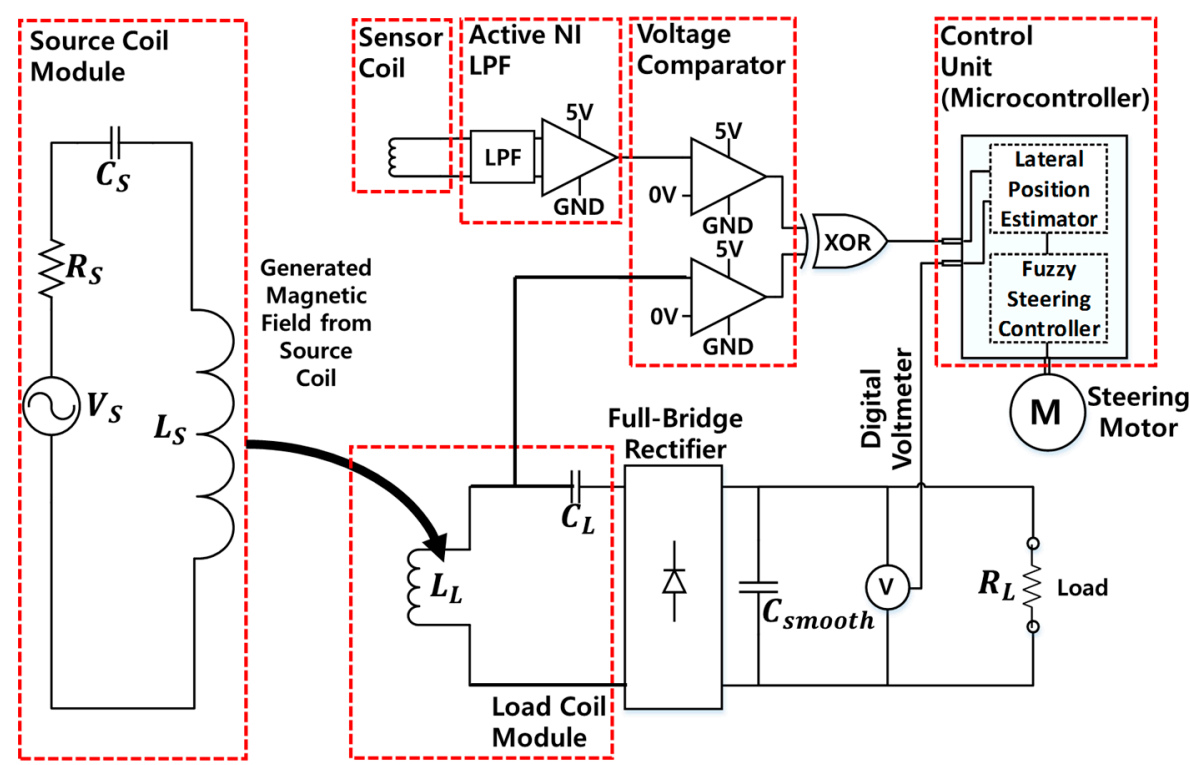

Figure 19. Overall circuit schematic for the experiment.

Table 4. Measured value of each components for the circuit schematic shown in Figure 19.

\begin{tabular}{ccc}
\hline Component & Symbol & Value \\
\hline & $L_{S}$ & $590.00 \mu \mathrm{H}$ \\
\cline { 2 - 3 } $\begin{array}{c}\text { Source/load coil components to } \\
\text { match resonance @ 20 kHz }\end{array}$ & $R_{S}$ & $170 \mathrm{~m} \Omega$ \\
\cline { 2 - 3 } & $C_{S}$ & $107.33 \mathrm{nF}$ \\
\cline { 2 - 3 } & $L_{L}$ & $186.15 \mu \mathrm{H}$ \\
\cline { 2 - 3 } & $R_{L}$ & $103 \mathrm{~m} \Omega$ \\
\hline Rectifier smoothing capacitor & $C_{L}$ & $328.11 \mathrm{nF}$ \\
\hline \multirow{2}{*}{\begin{tabular}{c} 
Low-pass filter (LPF) components \\
\cline { 2 - 3 }
\end{tabular}} & $C_{L P F}$ & $3200 \mu \mathrm{F}$ \\
\hline Load resistance for first experiment & $C_{L P F}$ & $919 \Omega$ \\
(static load) & $R_{L}$ & $10 \Omega$ \\
\hline $\begin{array}{c}\text { Load resistance for second experiment } \\
\text { (experimental vehicle load) }\end{array}$ & $R_{L}$ & $2 \sim 3 \Omega$ \\
\hline
\end{tabular}

In the first experiment (static load), the load coil was moved from $-8 \mathrm{~cm}$ (left) to $8 \mathrm{~cm}$ (right) in $1 \mathrm{~cm}$ increments. The change in voltage and current was monitored through the voltmeter and current meter, respectively, and recorded. Also, the changes in the load coil and sensor coil voltage waveforms were monitored through the oscilloscope as well. Because the power was reduced to $10 \mathrm{~W}$ in the second experiment (experimental vehicle load), the load coil was moved less; $-5 \mathrm{~cm}$ (left) to $5 \mathrm{~cm}$ (right) in $1 \mathrm{~cm}$ increments, unlike $\pm 8 \mathrm{~cm}$ in the first experiment. The sensor coil voltage waveform as well as its converted logic signals were monitored through the oscilloscope, and the detected voltage and steering position data were recorded through the microcontroller in the experimental vehicle.

\subsection{Experimental Results from the First Experiment (Static Load: 10 Ohm Resistor)}

Figure 20 shows the measured voltage and current as the load coil was moved from $-8 \mathrm{~cm}$ (left) to $8 \mathrm{~cm}$ (right) in $1 \mathrm{~cm}$ increments. Based on Figure 20, it can be seen that the power is significantly reduced when the lateral misalignment increases, both from the right side and left side. Half of the load 
coil's power was lost at $\pm 4 \mathrm{~cm}$, and nearly all of its power was lost at $\pm 8 \mathrm{~cm}$. The results in Figure 20 verify the theory explained in Section 2, and thus, justify the need for the proposed ACAS system.

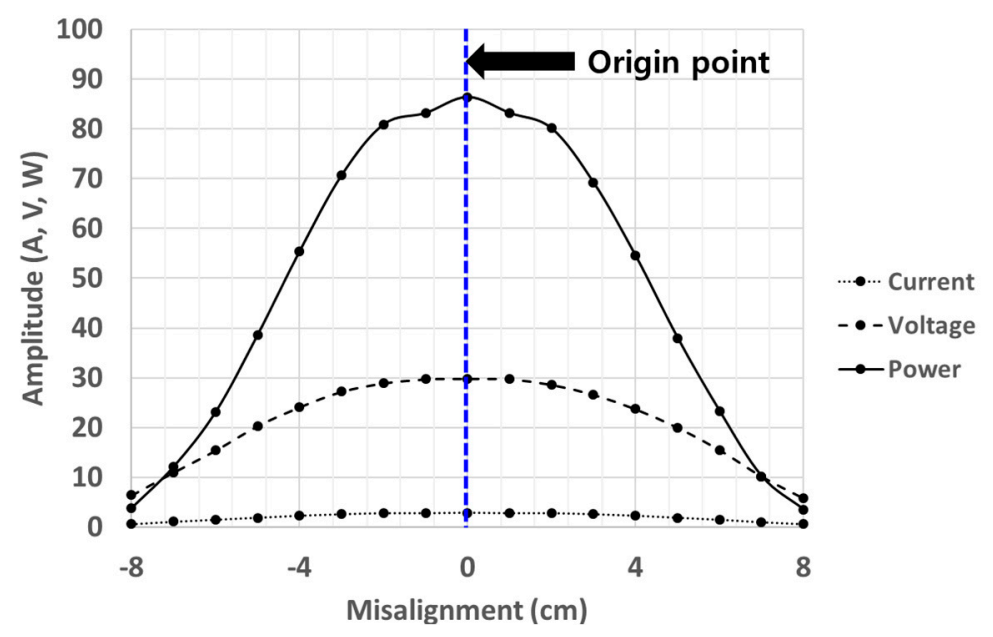

Figure 20. Voltage and current measured at the load, and its calculated power (first experiment: static load).

Figure 21 shows the voltage waveforms of the load coil and the sensor coil measured from the oscilloscope. Figure 21a,b represent when the load coil has a left misalignment, and a right misalignment, respectively. The captured results indicate that significant noise is present in the sensor coil waveform. These are filtered out through a low-pass filter before being converted into a logic signal as shown in the circuit schematic in Figure 19. Based on the results shown in Figure 21a, the phase difference between the load coil and sensor coil is 118.9 degrees (left misalignment), while the phase difference in Figure $21 \mathrm{~b}$ is -57.3 degrees (right misalignment). The difference between the two recorded phase values is 176.2 degrees, which is near the 180 phase angle difference described in the last paragraph in Section 3.1.

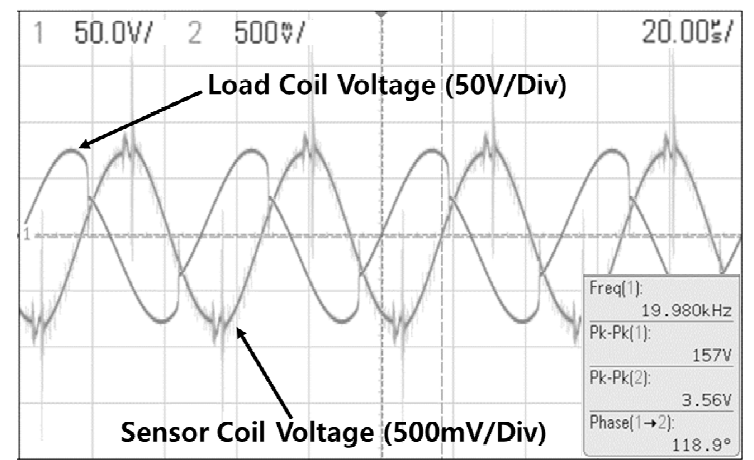

(a)

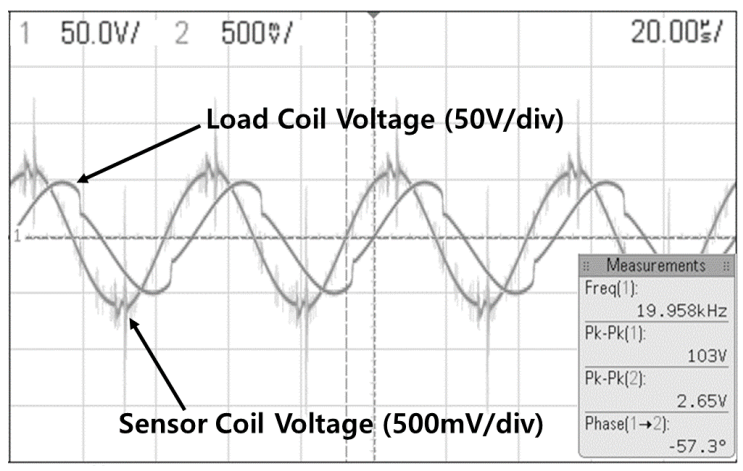

(b)

Figure 21. Oscilloscope readings from the first experiment showing the voltage waveform of the load coil and the sensor coil unit at (a) left misalignment; and (b) right misalignment.

\subsection{Experimental Results from the Second Experiment (Load: Experimental Vehicle)}

The recorded load coil and sensor coil waveforms for the second experiment are shown in Figure 22. These results show characteristics similar to the results shown in Figure 21, except there is a lower voltage amplitude, because the source coil was operating at a $10 \mathrm{~W}$ power level. Based on the recorded data, the phase of the sensor coil relative to the load coil for the left side (Figure 22a) 
and the right side (Figure 22b) are 139.5 degrees and -58.7 degrees, respectively, which makes the phase difference between left and right side 198.2 degrees. This slightly exceeds the theoretical 180 degree phase difference, but the difference between the left region and right region can still be clearly distinguished.

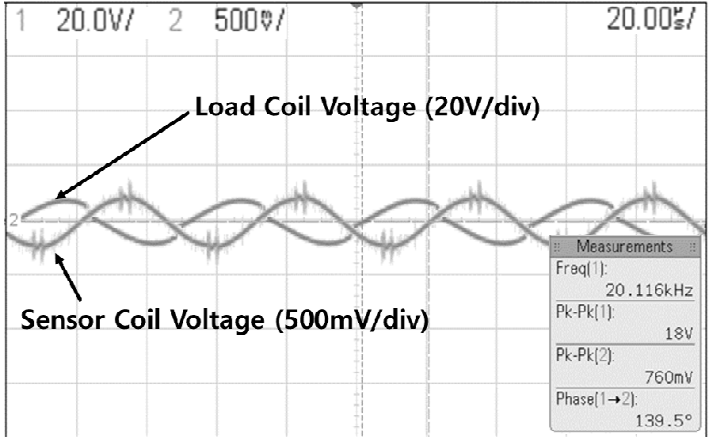

(a)

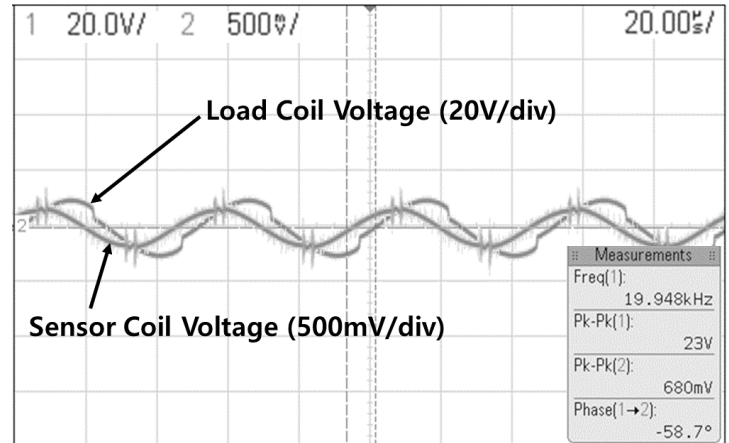

(b)

Figure 22. Oscilloscope readings from the second experiment showing the voltage waveform of the load coil and sensor coil unit at (a) left misalignment; and (b) right misalignment.

The waveforms (1) and (2) shown in Figure 23 show the converted square waveforms of the load coil and sensor coil outputs from Figure 22, respectively. These converted square waveforms are fed into the XOR gate, and the output signals are shown as waveform (3) in Figure 23. Figure 23a,b represent the left misalignment case and the right misalignment case, respectively. As can be seen from Figure 21, a phase difference between the load coil and sensor coil exists, thus the output generated by the XOR gate is an "unclean" HIGH or LOW logic output. However, it still verifies the concept illustrated in Figure 14.

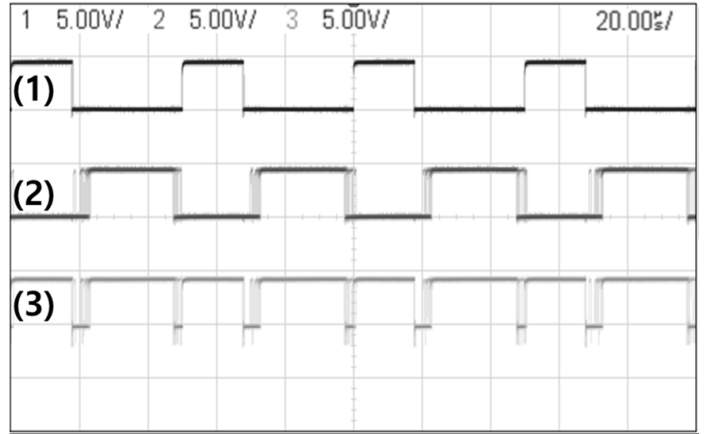

(a)

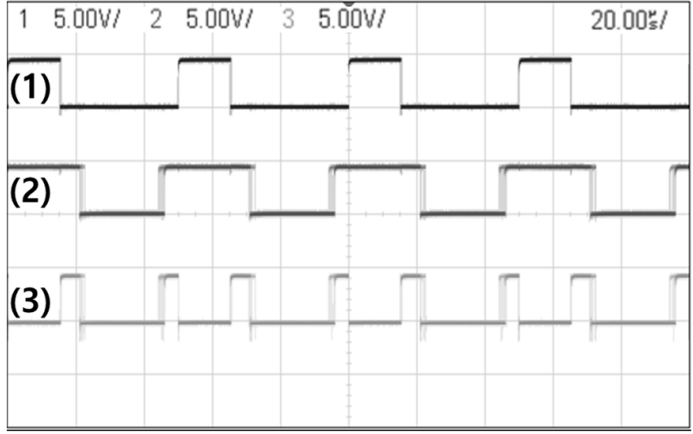

(b)

Figure 23. Oscilloscope readings from the second experiment showing the converted logic waveform of the (1) load coil; (2) sensor coil; and (3) the XOR gate output for (a) left misalignment; and (b) right misalignment.

To compensate the "unclean" signal from the two signals shown in waveform (3) in Figure 21a,b, a moving average filter was implemented in the main controller as follows:

$$
L P_{\text {total }}=\frac{1}{N} \sum_{j=0}^{N-1} L P[i+j]
$$

where $L P_{\text {total }}$ is the filtered lateral position output based on the number of samples, $N$. From this, the $L P$ described in Equation (10) can finally be identified, as follows: 


$$
L P=\left\{\begin{array}{c}
\text { left, } \\
\text { right, } L P_{\text {total }}>\text { if } L P_{\text {total }}<\text { threshold } \\
\text { righold }
\end{array}\right.
$$

where threshold is a certain fixed value used as a reference to compare with $L P_{\text {total }}$. The left or right position of the vehicle can be clearly distinguished when $L P_{\text {total }}$ is greater or lower than the threshold, respectively. Figure 24 illustrates the recorded DC voltage and current values as the vehicle was moved from left to right. These values have a trend similar to the data shown in Figure 20, where power decreased significantly with increasing misalignment. The data from Figure 24 were used to determine the relationship between voltage and misalignment distance, $f\left(V_{L}\right)$, shown in Equation (10), which came out as $y=-0.1834 x^{2}-0.055 x+6.7756$. In the equation, $\mathrm{x}$ is the measured voltage, and $\mathrm{y}$ is the determined misalignment range output.

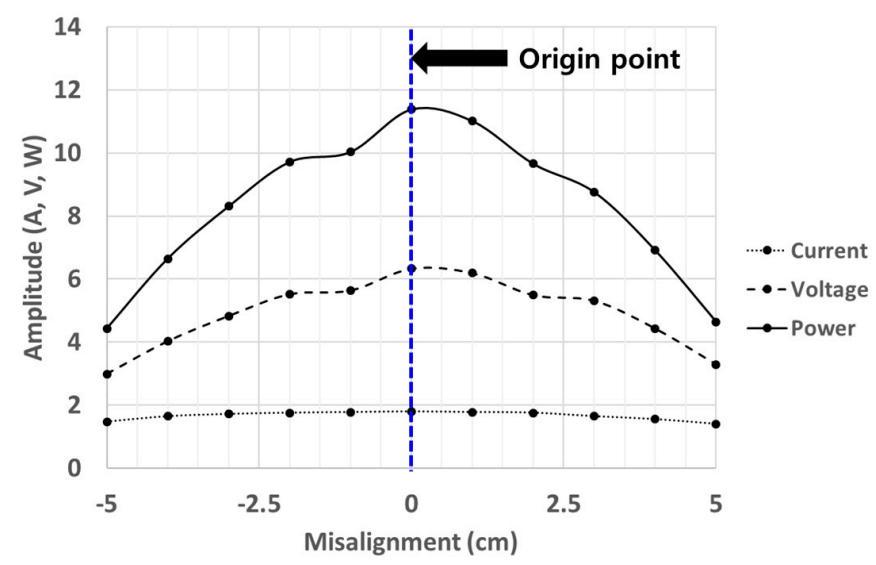

Figure 24. Voltage and current measured at the load, and its calculated power, and its calculated power (second experiment: experimental vehicle load).

Figure 25 shows the data acquired from the experimental vehicle from the second experiment, indicating the estimated lateral misalignment based on voltage readings from the digital voltmeter, and the determined left/right region from the sensor coil. The negative values and positive values on the misalignment range axis are the left and right lateral misalignment location values, respectively. It can be observed that the vehicle's position is always above or below the origin point $(0 \mathrm{~cm})$. This is because a tolerance range has been assigned in the fuzzy steering controller, which is $\pm 1.7 \mathrm{~cm}$ at the origin point. If the desired position was set at the origin point $(0 \mathrm{~cm})$, it can be expected that continuous steering oscillations will occur, which is undesirable for both the vehicle's safety and comfort.

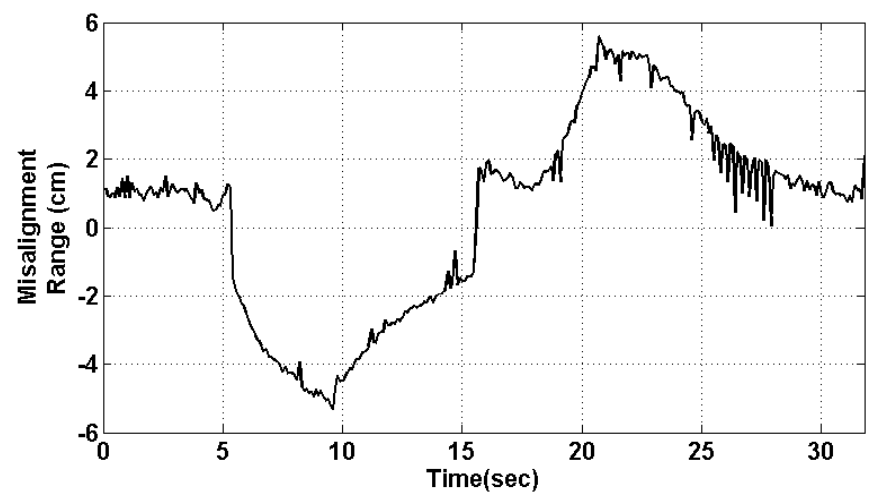

Figure 25. Estimated misalignment range from the ACAS controller based on voltage readings and the left/right position given by the sensor coil. 
Based on the estimated lateral misalignment values, the steering can be controlled, as shown in the experimental vehicle's recorded data in Figure 26. It should be noted that the experimental setup differs greatly from a real driving environment, because the vehicle's lateral position was forcibly changed using the acrylic plate. However, the test demonstrates that the fuzzy controller designed in [24] outputs a steering value corresponding to the lateral misalignment position, thus verifying the feasibility of the operating concept of the autonomous steering control.

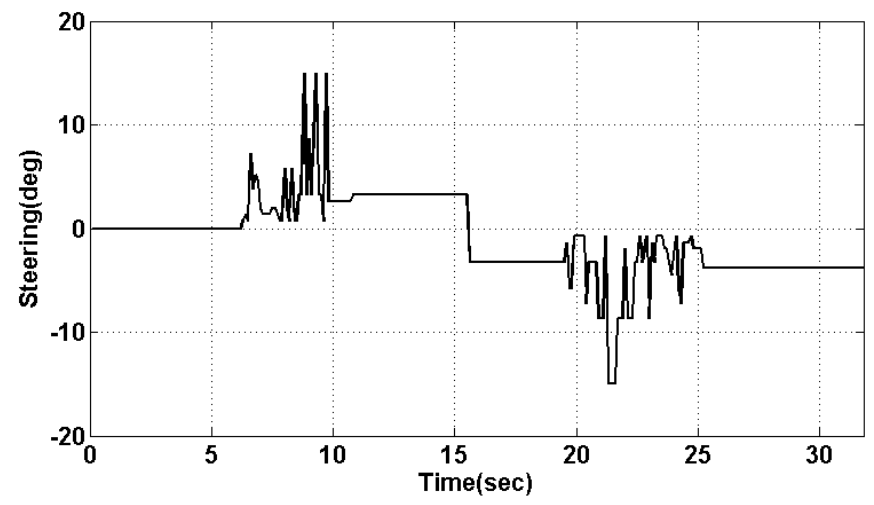

Figure 26. Steering angle output generated by the Fuzzy steering controller designed in [24] based on the estimated lateral misalignment shown in Figure 22.

Figure 27 shows the estimated power received in the load coil of the experimental vehicle. The estimated power is the product of voltage and current. The voltage was measured by a digital voltmeter installed in the vehicle. The current can be calculated by finding the relationship function between voltage and current based on Figure 24. The figure shows that when the vehicle's load coil is aligned with the source coil, roughly $11 \mathrm{~W}$ of power is received, and when the vehicle is at a $\pm 5 \mathrm{~cm}$ lateral misalignment, the received power falls to roughly $4 \mathrm{~W}$. This indicates that the received power is reduced by more than two thirds of its maximum level, which can result in a significant loss in the vehicle's driving range.

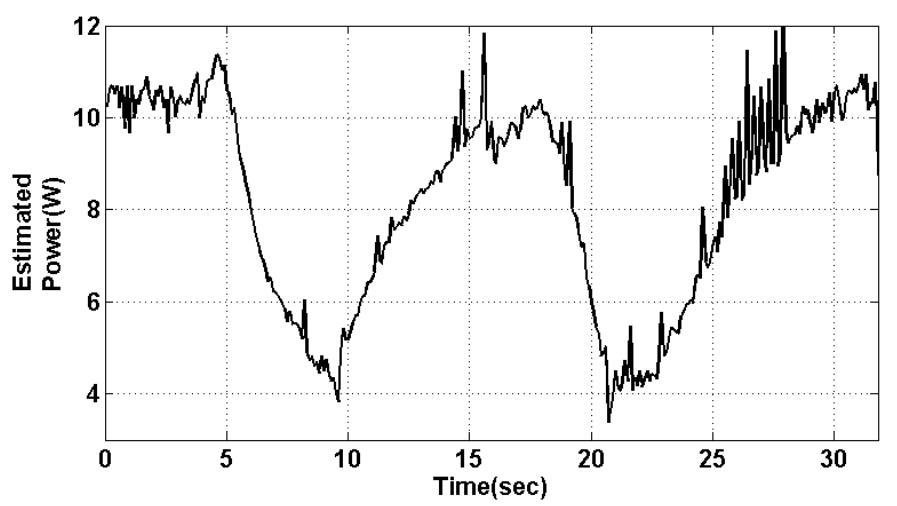

Figure 27. Estimated power received by the load coil of the experimental vehicle during the second experiment.

To show the significance of the ACAS, an analysis comparing the generated energy of a vehicle with ACAS and without ACAS was conducted. Here, two assumptions are made:

1. For the vehicle without ACAS, the estimated power shown in Figure 27 was assumed to be the level of power that would actually be received by the DWC vehicle while in operation.

2. For the vehicle with ACAS, it was assumed that a constant $11 \mathrm{~W}$ of power is generated, as the vehicle's load coil is kept in constant alignment with the source coil on the road. 
Based on these two assumptions, an analysis comparing the energy accumulated by the vehicle with ACAS and the vehicle without ACAS was conducted, and the results are shown in Figure 28. The recorded accumulated energy at the 30 second mark (shown in Figure 28) is $0.067 \mathrm{Wh}$ for the vehicle without ACAS, and $0.091 \mathrm{Wh}$ for the vehicle with ACAS, respectively. Assuming that the experiment continued at this rate for an hour, the total accumulated energies would be $8.04 \mathrm{Wh}$ and $10.92 \mathrm{Wh}$ for the vehicle without ACAS and the vehicle with ACAS, respectively. Based on these values, the vehicle with the ACAS received $26 \%$ more accumulated energy than the vehicle without the ACAS.

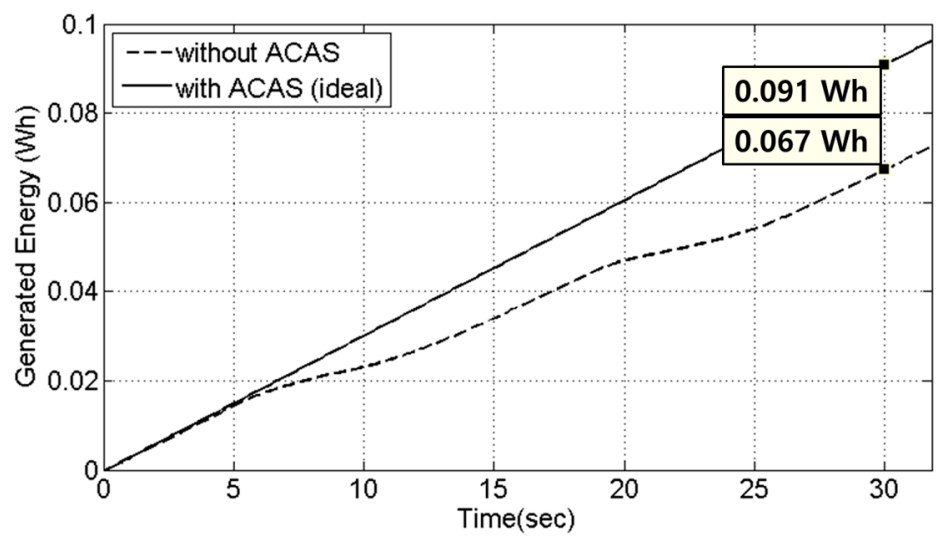

Figure 28. Comparison of estimated energy accumulated by a vehicle with ACAS and a vehicle without ACAS (based on generated power in the load coil shown in Figure 24).

\section{Conclusions}

This paper has proposed an ACAS for EVs with DWC to maximize the power delivered to the load coil, by keeping the vehicle aligned with the source coil as much as possible. The proposed ACAS system was verified through simulations and experiments. Two separate experiments were conducted at different power levels. One was conducted at $\sim 90 \mathrm{~W}$, and the other at $\sim 10 \mathrm{~W}$. The experiments verified the operating concept of the sensor coil, which is the key component used to determine the left/right side misalignment. In addition, an analysis based on the results of the second experiment demonstrated the advantage of the proposed ACAS in the vehicle, where $26 \%$ more energy could be accumulated by keeping the vehicle's load coil aligned with the source coil. By incorporating an improved steering controller which has a faster response to the vehicle's characteristics, it can be expected that more energy could be saved. The ACAS provides a solution to resolve the reduction in power received in the load coil during DWC due to misalignment, and ultimately provide higher efficiency and longer driving ranges for EVs with DWC.

Supplementary Materials: The following are available online at www.mdpi.com/1996-1073/10/3/315/s1, Video S1: video showing the overall operation of the autonomous coil alignment system (ACAS). It can be seen that the vehicle's steering position is autonomously adjusted once significant misalignment is detected.

Acknowledgments: This research was supported by the MSIP (Ministry of Science, ICT and Future Planning), Korea, under the ITRC (Information Technology Research Center) support program (IITP-2016-R2718-16-0012) supervised by the IITP (National IT Industry Promotion Agency) and the IT R\&D program of MSIP/IITP. (B0138-16-1002, Study on the EMF exposure control in smart society).

Author Contributions: Karam Hwang conceived and designed the experiments; Karam Hwang performed the experiments; Karam Hwang, Jaeyong Cho, Dongwook Kim, and Jaehyoung Park, and Seungyoung Ahn analyzed the data; Jong Hwa Kwon, Sang Il Kwak, Hyun Ho Park, and Seungyoung Ahn contributed reagents/materials/analysis tools; Karam Hwang and Seungyoung Ahn wrote the paper.

Conflicts of Interest: The authors declare no conflict of interest. 


\section{References}

1. Aziz, M.; Oda, T.; Mitani, T.; Watanabe, Y.; Kashiwagi, T. Utilization of Electric Vehicles and Their Used Batteries for Peak-Load Shifting. Energies 2015, 8, 3720-3738. [CrossRef]

2. Cao, C.; Wang, L.; Chen, B. Mitigation of the Impact of High Plug-in Electric Vehicle Penetration on Residential Distribution Grid Using Smart Charging Strategies. Energies 2016, 9, 1024. [CrossRef]

3. Tan, L.; Liu, H.; Liu, Z.; Guo, J.; Yan, C.; Wang, W.; Huang, X. Power Stabilization Strategy of Random Access Loads in Electric Vehicles Wireless Charging System at Traffic Lights. Energies 2016, 9, 811. [CrossRef]

4. Choi, S.Y.; Gu, B.W.; Jeong, S.Y.; Rim, C.T. Advances in wireless power transfer systems for roadway-powered electric vehicles. IEEE J. Sel. Top. Power Electron. 2015, 3, 18-36. [CrossRef]

5. Shekhar, A.; Prasanth, V.; Bauer, P.; Bolech, M. Economic Viability Study of an On-Road Wireless Charging System with a Generic Driving Range Estimation Method. Energies 2016, 9, 76. [CrossRef]

6. Nagendra, G.R.; Chen, L.; Covic, G.A.; Boys, J.T. Detection of EVs on IPT highways. IEEE J. Sel. Top. Power Electron. 2014, 2, 584-597. [CrossRef]

7. Jang, Y.J.; Jeong, S.; Lee, M.S. Initial Energy Logistics Cost Analysis for Stationary, Quasi-Dynamic, and Dynamic Wireless Charging Public Transportation Systems. Energies 2016, 9, 483. [CrossRef]

8. Chen, Z.; Jing, W.; Huang, X.; Tan, L.; Chen, C.; Wang, W. A Promoted Design for Primary Coil in Roadway-Powered System. IEEE Trans. Magn. 2015, 51, 8402004. [CrossRef]

9. Chen, W.; Liu, C.; Lee, C.H.; Shan, Z. Cost-Effectiveness Comparison of Coupler Designs of Wireless Power Transfer for Electric Vehicle Dynamic Charging. Energies 2016, 9, 906. [CrossRef]

10. Chow, J.P.; Chen, N.; Chung, S.H.; Chan, L.L. An investigation into the use of orthogonal winding in loosely coupled link for improving power transfer efficiency under coil misalignment. IEEE Trans. Power Electron. 2015, 30, 5632-5649. [CrossRef]

11. Choi, S.Y.; Jeong, S.Y.; Lee, E.S.; Gu, B.W.; Lee, S.W.; Rim, C.T. Generalized models on self-decoupled dual pick-up coils for large lateral tolerance. IEEE Trans. Power Electron. 2015, 30, 6434-6445. [CrossRef]

12. Kalwar, K.A.; Mekhilef, S.; Seyedmahmoudian, M.; Horan, B. Coil Design for High Misalignment Tolerant Inductive Power Transfer System for EV Charging. Energies 2016, 9, 937. [CrossRef]

13. Shin, J.; Shin, S.; Kim, Y.; Ahn, S.; Lee, S.; Jung, G.; Jeon, S.; Cho, D. Design and implementation of shaped magnetic-resonance-based wireless power transfer system for roadway-powered moving electric vehicles. IEEE Trans. Ind. Electron. 2014, 61, 1179-1192. [CrossRef]

14. Kim, J.; Kim, J.; Kong, S.; Kim, H.; Suh, I.; Suh, N.; Cho, D.; Kim, J.; Ahn, S. Coil design and shielding methods for a magnetic resonant wireless power transfer system. Proc. IEEE 2013, 101, 1332-1342. [CrossRef]

15. Gao, Y.; Farley, K.B.; Tse, Z.T.H. A Uniform Voltage Gain Control for Alignment Robustness in Wireless EV Charging. Energies 2015, 8, 8355-8370. [CrossRef]

16. Hu, P.; Ren, J.; Li, W. Frequency-Splitting-Free Synchronous Tuning of Close-Coupling Self-Oscillating Wireless Power Transfer. Energies 2016, 9, 491. [CrossRef]

17. Federal Highway Administration. Available online: http://safety.fhwa.dot.gov/geometric/pubs/ mitigationstrategies/chapter3/3_lanewidth.cfm (accessed on 15 October 2014).

18. Hernandez, J.I.; Kuo, C. Steering control of automated vehicles using absolute positioning GPS and magnetic markers. IEEE Trans. Veh. Technol. 2003, 52, 150-161. [CrossRef]

19. Ryu, H.; Har, D. Wireless power transfer for high-precision position detection of railroad. In Proceedings of the IEEE Power, Communication and Information Technology Conference (PCITC), Bhubaneswar, India, 15-17 October 2015; pp. 605-608.

20. Chen, S.; Liao, C.; Wang, L. Research on positioning technique of wireless power transfer system for electric vehicles. In Proceedings of the IEEE Conference and Expo Transportation Electrification Asia-Pacific (ITEC Asia-Pacific), Beijing, China, 31 August-3 September 2014; pp. 1-4.

21. Choi, Y.; Kang, D.; Lee, S.; Kim, Y. The autonomous platoon driving system of the on line electric vehicle. In Proceedings of the ICROS-SICE International Joint Conference, Fukuoka, Japan, 18-21 August 2009; pp. 3423-3426.

22. Xu, H.; Yang, M.; Wang, C.; Yang, R. Magnetic sensing system design for intelligent vehicle guidance. IEEE/ASME Trans. Mechatron. 2010, 15, 652-656.

23. Byun, Y.-S.; Jeong, R.-G.; Kang, S.-W. Vehicle Position Estimation Based on Magnetic Markers: Enhanced Accuracy by Compensation of Time Delays. Sensors 2015, 15, 28807-28825. [CrossRef] [PubMed] 
24. Hwang, K.; Park, J.; Kim, D.; Park, H.H.; Kwon, J.H.; Kwak, S.I.; Ahn, S. Autonomous Coil Alignment System Using Fuzzy Steering Control for Electric Vehicles with Dynamic Wireless Charging. Math. Probl. Eng. 2015, 2015, 205285. [CrossRef]

25. Kim, J.; Lee, B.; Lee, S.; Park, C.; Jung, S.; Lee, S.; Yi, K.; Baek, J. Development of 1-MW inductive power transfer system for a high-speed train. IEEE Trans. Power Electron. 2015, 62, 6242-6249. [CrossRef]

26. Ko, Y.; Jang, Y. The optimal system design of the online electric vehicle utilizing wireless power transmission technology. IEEE Trans. Intell. Transp. Syst. 2013, 14, 1255-1265. [CrossRef]

27. Cheng, C.-H. Implementation of a Small Type DC Microgrid Based on Fuzzy Control and Dynamic Programming. Energies 2016, 9, 781. [CrossRef]

28. Sayed, K.; Gabbar, H.A. Electric Vehicle to Power Grid Integration Using Three-Phase Three-Level AC/DC Converter and PI-Fuzzy Controller. Energies 2016, 9, 532. [CrossRef]

(C) 2017 by the authors. Licensee MDPI, Basel, Switzerland. This article is an open access article distributed under the terms and conditions of the Creative Commons Attribution (CC BY) license (http:/ / creativecommons.org/licenses/by/4.0/). 